\title{
Matching behavior and deprivation
}

\author{
BRUCE A. WALD and CARL D. CHENEY \\ Utah State University, Logan, Utah 84322
}

\begin{abstract}
Four White Carneaux pigeons were trained to respond for food on concurrent variable interval reinforcement schedules. Their weights were systematically established at $73 \%, 80 \%, 87 \%$, and $94 \%$ of ad lib. As weight increased, relative response rate and the relative time spent in the more dense schedule remained constant, while post reinforcement pause increased. There was less variation in time allocation than response ratios.
\end{abstract}

The effect of different levels of food deprivation on relative and absolute response rates has received considerable experimental attention (cf. Bolles, 1967). After depriving three groups of rats for up to $23 \mathrm{~h}$, Clark (1958) reinforced each according to a different variable-interval (VI) schedule. Response rates increased with increased deprivation time, but the ratio of responses between the various schedules remained constant over deprivation conditions. Dinsmoor (1952) developed the ratio of responses made during the reinforcement component to responses made during the extinction component of a multiple schedule. The absolute rates of responding increased systematically in both components as deprivation (measured as percentage of free-feeding weight) increased. But, once again, there was no change in the ratio of response rates between reinforcement and extinction periods.

Powell (1973), on the other hand, has suggested that the degree of stimulus control over a pigeon's behavior, in an experimental situation, determines the invariance of the ratio of the response rates. Under conditions similar to Dinsmoor (1952), Powell showed that response in extinction, relative to reinforced responding, changed as deprivation increased when stimulus control was weak. The response ratio was not affected, however, when stimulus control was strong. This constancy of response ratios (under conditions of strong stimulus control) over changes in deprivation levels is provocative, for it is just such invariances that provide leverage in the construction of general laws of behavior. This particular invariance suggests that behavior ratios (cf. Herrnstein, 1961; Tolman, 1951) may provide an index that is robust in the face of changing deprivation levels, even within the course of an experimental session (Lydersen $\&$ Cheney, 1973). More importantly and for many purposes, such a measure avoids the difficult, if not insoluble problem of equating deprivation levels across species.

In the context of concurrent reinforcement schedules, the behavior ratio has been the dependent variable of choice (see, e.g., Baum and Rachlin, 1969; Rachlin,

The authors wish to thank G. Opfer, M. Newsom, and, especially, P. Killeen for suggestions on earlier drafts of this paper. This study was conducted while the first author was a Master's Degree candidate at Arizona State University.
1971). But it has never been clearly demonstrated that the behavior ratio in concurrent schedules (i.e., the rate of responding on one schedule divided by the rate on the other) is invariant over deprivation level. The issue of deprivation invariance is now especially cogent, for there are two different ways of measuring a behavior ratio, and each has its own proponents. Herrnstein (1970) suggests consideration of the ratio of responses emitted on each of the schedules (or, the proportion of responses, which conveys the same information and is easily transformed into a ratio). Baum and Rachlin (1969) endorse the ratio of time spent responding on each of the schedules. The criterion by which these measures have been evaluated has been the "matching law" (cf. Rachlin, 1971); behavior ratios, it is argued, should equal the ratio of reinforcers (or reinforcer amount, or reinforcer immediacy) delivered by the respective schedules. Whichever form of the behavior ratio comes closest to this prediction gains support. The concept of invariance provides a less theory-bound criterion, i.e., that form which is independent of changes in certain variables is, for many purposes, the preferred variable. In the present study, both forms were tested for invariance across a range of deprivation levels.

\section{METHOD}

\section{Subjects}

Four White Carneaux pigeons, approximately 4 years of age, were maintained at $80 \%$ of free-feeding weight during baseline conditions. Other weight changes are described below. All four pigeons had extensive experimental histories.

\section{Apparatus}

A Lehigh Valley three-key chamber was used. Each key required a minimum force of $0.1 \mathrm{~N}$ for operation, and could be illuminated white, green, or red. During the baseline condition, only the side keys were used; but, during the weight manipulation conditions, all three keys were used. Ventilation and masking noise were provided by an exhaust fan. Electromechanical equipment programmed experimental events and recorded responses and latencies.

\section{Procedure}

During each session, 42 reinforcers were programmed for one key and 18 for the other. One VI 50 -sec tape programmed reinforcers, which were allocated to one or the other side key in 
Table 1

Order of Presentation and Number of Sessions (in Parentheses) at Each Weight Condition

\begin{tabular}{rcccccccc}
\hline Subject & \multicolumn{2}{c}{$73 \%$} & \multicolumn{2}{c}{$80 \%$} & \multicolumn{2}{c}{$87 \%$} & \multicolumn{2}{c}{$94 \%$} \\
\hline 673 & 3 & $(14)$ & 1 & $(12)$ & 4 & $(19)$ & 2 & $(41)$ \\
7915 & 1 & $(24)$ & 4 & $(15)$ & 2 & $(19)$ & 3 & $(51)$ \\
1596 & 2 & $(18)$ & 3 & $(13)$ & 1 & $(22)$ & 4 & $(13)$ \\
1952 & 4 & $(24)$ & 2 & $(13)$ & 3 & $(13)$ & 1 & $(15)$ \\
\hline
\end{tabular}

pseudorandom order, effectively making the schedule concurrent VI $71 \mathrm{sec}$ VI $167 \mathrm{sec}$. Pecking either key occasionally resulted in $3 \mathrm{sec}$ access to mixed grain. When a pigeon switched from pecking one side key to the other, a response to the second key could not be reinforced for $2.5 \mathrm{sec}$.

In the baseline condition, each pigeon was kept at $80 \%$ of its free-feeding weight while exposed to the concurrent schedule. Treatment sessions were run with each bird's weight established at $73 \%, 87 \%, 80 \%$, and $94 \%$. Table 1 shows the order and number of sessions at each weight level for each pigeon. Conditions were changed when both relative and absolute time and response measures appeared stable by visual inspection.

The middle key was used only in the treatment conditions. At the beginning of each session, and following reinforcement, the middle key was white while the two side keys were dark and inoperative. A peck to the illuminated middle key turned it off subjects (1596 and 1952) decreased relative response output. The deviation of individual averages from the mean at each deprivation condition was greater for responses than for time ( $5.5 \%$ vs. $4.0 \%)$.

Neither proportion of responses, nor proportion of time, "matched" the proportion of reinforcers received on the VI 71 schedule (70\%) (cf. Baum, 1974). Although "under-matching" on concurrents is common, investigations employing programming techniques similar to those used in the present study have also found slight "over-matching" (Stubbs and Pliskoff, 1969).

Some investigators have made a case for time allocation as the fundamental dependent variable in describing concurrent performance (Baum \& Rachlin, 1969; Killeen, 1972; Premack, 1965; Rachlin, 1971). While consistent with that viewpoint, the present data add little direct support. Rather, the results suggest that both rate and time dependent variables remained generally invariant with deprivation level.

"Best" descriptions may be taken as those which account for most of the variance in behavior, (or rather,

Table 2

Summary of Dependent Measures

\begin{tabular}{|c|c|c|c|c|c|c|c|c|c|c|c|c|}
\hline \multirow[b]{2}{*}{ Subject } & \multicolumn{4}{|c|}{ Relative Time } & \multicolumn{4}{|c|}{ Relative Responses } & \multicolumn{4}{|c|}{ Latency/60 Reinforcers } \\
\hline & $73 \%$ & $80 \%$ & $87 \%$ & $94 \%$ & $73 \%$ & $80 \%$ & $87 \%$ & $94 \%$ & $73 \%$ & $80 \%$ & $87 \%$ & $94 \%$ \\
\hline $\begin{array}{r}673 \\
7915 \\
1596 \\
1952\end{array}$ & $\begin{array}{l}.73 \\
.84 \\
.82 \\
.79\end{array}$ & $\begin{array}{l}.80 \\
.80 \\
.84 \\
.74\end{array}$ & $\begin{array}{l}.70 \\
.78 \\
.74 \\
.76\end{array}$ & $\begin{array}{l}.82 \\
.82 \\
.86 \\
.71\end{array}$ & $\begin{array}{l}.74 \\
.80 \\
.83 \\
.86\end{array}$ & $\begin{array}{l}.68 \\
.77 \\
.80 \\
.82\end{array}$ & $\begin{array}{l}.73 \\
.85 \\
.71 \\
.80\end{array}$ & $\begin{array}{l}.79 \\
.84 \\
.63 \\
.65\end{array}$ & $\begin{array}{r}8.8 \\
11.5 \\
11.2 \\
10.8\end{array}$ & $\begin{array}{r}7.3 \\
16.4 \\
15.3 \\
13.1\end{array}$ & $\begin{array}{c}14.9 \\
66.7^{*} \\
7.2 \\
16.0\end{array}$ & $\begin{array}{c}23.4 \\
66.7 * \\
29.9 \\
8.2\end{array}$ \\
\hline Average & .80 & .80 & .75 & .80 & .81 & .77 & .77 & .73 & 10.6 & 13.0 & 26.2 & 32.0 \\
\hline $\begin{array}{l}\text { Average } \\
\text { Deviation }\end{array}$ & .04 & .03 & .03 & .06 & .05 & .04 & .05 & .09 & .9 & 2.9 & 20.2 & 17.3 \\
\hline
\end{tabular}

*The majority of these sessions exceeded the 4000-sec termination criterion.

and illuminated the two side keys white. Responses to, and time spent on, the side keys were recorded only when those keys were lit. Latency was measured as the total time that the middle key was on during a session divided by the number of reinforcers obtained in that session. Sessions terminated when total latency reached $4,000 \mathrm{sec}$ or 60 reinforcers were delivered.

\section{RESULTS AND DISCUSSION}

Table 2 gives the relevant data. Across all conditions, the pigeons spent $78.4 \%$ of their time on the VI 71 schedule where they emitted $76.8 \%$ of their responses. As expected, latency increased with increases in body weight (cf. Powell, 1973). However, the relative time spent responding on each of the schedules did not change a great deal as a function of body weight; neither was there a systematic change in the relative number of responses made in each schedule. Two subjects (673 and $7915)$ tended to respond relatively more in the VI 71-sec schedule as their weights increased, while the other two parcel the behavior so that there is little variance left to account for). There is certainly less variance to account for in time ratios than response ratios in the present study.

\section{REFERENCES}

Baum, W. M. On two types of deviation from the matching law: Bias under-matching. Journal of the Experimental Analysis Behavior, 1974, 22, 231-242.

Baum, W. M., \& Rachlin, H. Choice as time allocation. Journal of the Experimental Analysis of Behavior, 1969, 12, 861-874.

Bolles, R. C. Theory of motivation. New York: Harper and Row, 1967.

Clark, F. C. The effect of deprivation and frequency of reinforcement on variable-interval responding. Journal of the Experimental Analysis of Behavior, 1958, 1, 221-228.

Dinsmoor, J. A. The effect of hunger on discriminated responding. Journal of Abnormal and Social Psychology, $1952,47,67-72$

Herrnstein, R. J. Relative and absolute strength of a response as a function of frequency of reinforcement. Journal of the Experimental Analy sis of Behavior, 1961, 4, 267-272.

Herrnstein, R. J. On the law of effect. Journal of the Experimental Analysis of Behavior, 1970, 13, 243-266.

Killeen, P. A yoked-chamber comparison of concurrent and multiple schedules. Journal of the Experimental Analy sis of Behavior, 1972, 18, 13-22. 
Lydersen, T., \& Cheney, C. D. Fixed-ratio discrimination effects of extinction and satiation. The Journal of Biological Psy chology, 1973, 15, 26-29.

Powell, R. W. Effects of stimulus control and deprivation upon discriminative responding. Journal of the Experimental Analy sis of Behavior, 1973, 19, 351-360.

Premack, D. Reinforcement theory. In D. Levine (Ed.), Nebraska Symposium on Motivation. Lincoln: University of Nebrask Press, 1965. Pp. 123-180.
Rachlin, H. C. On the tautology of the matching law. Journal of the Experimental Analysis of Behavior, 1971, 15, 249-251.

Stubbs, D. A., \& Pliskoff, S. S. Concurrent responding with fixed relative rate of reinforcement. Journal of the Experimental Analy sis of Behavior, 1969, 12, 887-895.

Tolman, E. C. Behavior and psychological man. Berkeley: University of California Press, 1951. P. 145.

(Received for publication March 3, 1975.) 